CONSIDERAÇÕES HISTORIOGRÁFICAS SOBRE A PARTICIPAÇÃO BRASILEIRA NA SEGUNDA GUERRA MUNDIAL: BALANÇO DA PRODUÇÃO BIBLIOGRÁFICA E SUAS TENDÊNCIAS

\author{
HISTORIOGRAPHICAL CONSIDERATIONS ON THE \\ BRAZILIAN PARTICIPATION IN WORLD WAR II: \\ EVALUATION OF BIBLIOGRAPHIC PRODUCTION AND \\ ITS TRENDS*
}

Francisco Cesar Alves Ferraz**

\begin{abstract}
Resumo: O objetivo deste artigo é analisar a bibliografia publicada, no período entre 1945 e 2015, sobre a participação brasileira na Segunda Guerra Mundial. Essa pesquisa compreendeu livros, capítulos de livros, artigos em periódicos acadêmico-científicos e profissionais militares, artigos em revistas de divulgação científica, teses, dissertações e monografias acadêmicas e trabalhos publicados em anais de eventos acadêmicos.Os procedimentos do estudo consistiram em três fases: a) análise estatística; b) verificação de tendências históricas de publicação; c) discussão dos problemas práticos de pesquisa e de natureza editorial dessa área de estudo.A conclusão do trabalho é a de que há uma significativa bibliografia da participação brasileira na Segunda Guerra Mundial, a despeito da crença comum de que usualmente considera que há pouco interesse nesse tema na historiografia profissional e na opinião pública. Muito pelo contrário, o que se verificou foi que a produção bibliográfica é quantitativamente expressiva (1092 títulos em 70 anos) e, em termos historiográficos, de crescente qualidade e variedade. Ademais, há uma crescente produção envolvendo grupos maiores e mais diversificados de pesquisadores e autores e, por fim mas não menos importante, um estimulante conjunto de abordagens mais interessantes, complexas e melhor fundamentadas.
\end{abstract}

Palavras-chave: Brasil e a Segunda Guerra Mundial; historiografia; Força 


\title{
Expedicionária Brasileira.
}

\begin{abstract}
The aim of this article is to analyze the bibliography on Brazilian participation in World War II, published in the period between 1945 and 2015. This research encompassed books, book chapters, articles in scientific and professional-military journals, articles in scientific popularization articles, $\mathrm{PhD}$ and Master Degree dissertations and academic monographs and papers published in annals of academic conferences. The procedures of study were conducted in three phases: a) statistical analysis; b) verification of historical trends of publishing; c) exam of practical problems on researching and publishing on this area of study. The conclusion of the work is that there is a significant bibliography of the Brazilian participation in World War II, despite the common belief that usually considers that there is little interest in this subject in professional historiography and public opinion. Instead, what we found was that the bibliographic production is quantitatively significant (1092 titles in 70 years) and of increasing quality and variety, in historiographical terms. Moreover, there is an increasing bibliographical production involving larger and more diverse groups of researchers and authors and, last but not least a stimulating set of most interesting, complex and better founded approaches.
\end{abstract}

Keywords: Brazil and World War II; historiography; Brazilian Expeditionary Force.

\footnotetext{
* Este artigo apresenta resultados do projeto de pesquisa Força Expedicionária Brasileira, História e Historiografia, contemplado com Bolsa Pesquisador- Produtividade do CNPq, entre 2010 e 2013.
}

**Universidade Estadual de Londrina, Paraná, Brasil. E-mail: fcaferraz@yahoo.com.br 


\section{Introdução}

A Segunda Guerra Mundial foi um divisor de águas na história e na historiografia do século XX. Seu impacto global, as suas causas, seu desenvolvimento, as consequências que legou, direta ou indiretamente, para a população civil e para os combatentes, são objetos de intenso debate em todo o mundo. Mais que nenhuma outra, essa guerra ocupa espaço privilegiado na indústria editorial, no cinema ficcional e documental, na cultura popular. Por décadas, seus combatentes-sobreviventes, bem como os cidadãos da população civil, têm expressado e transmitido para a posteridade, de forma oral ou escrita, suas memórias.

O Brasil participou, de maneira modesta se comparado com as grandes potências beligerantes, da Segunda Guerra Mundial. Sua participação se deu em três modalidades: primeiro, como fornecedor de matérias-primas estratégicas para os Aliados; em seguida, cedendo, para uso dos Aliados, bases aéreas e navais no Norte e Nordeste do país; finalmente, após o afundamento de navios mercantes em pleno litoral brasileiro, por submarinos do Eixo e a declaração de beligerância, pelo envio de uma força expedicionária para combater no Teatro de Operações do Mediterrâneo.

Apesar desse conflito provocar, no mundo todo, um amplo debate e interesse historiográfico, há no Brasil uma crença comum de que há pouco ou nenhum interesse pela história da participação do país na Segunda Guerra Mundial, principalmente por parte da historiografia profissional universitária. Essa percepção de senso comum se deve a alguns fatores:

- abordagem rarefeita ou mesmo inexistente do tema nos cursos de graduação e pós-graduação em História;

- espaço dedicado ao tema cada vez menor nos livros didáticos;

- tema pouco presente nas pautas das principais editoras do país

Segundo esse mesmo senso comum que se queixa da pouca importância conferida à participação brasileira na Segunda Guerra Mundial, as pricipais razões seriam:

- visão comum de que a participação brasileira no conflito foi insignificante;

- identificação generalizada da participação brasileira como uma ação exclusiva ou predominante das Forças Armadas;

- tendência laudatória da bibliografia sobre a participação do país na guerra, especialmente as ações de combate da Força Expedicionária Brasileira (doravante, FEB) e do grupo de caça da Força Aérea Brasileira (doravante, FAB);

- identificação das lideranças militares que participaram da guerra com as forças armadas que protagonizaram o golpe de Estado de 1964.

Este artigo propõe uma análise, quantitativa e qualitativa, da produção bibliográfica sobre as diversas dimensões da participação brasileira na Segunda 
Guerra Mundial. Para esse fim foi efetuado um levantamento sobre a produção bibliográfica de livros, capítulos de livros, artigos em periódicos acadêmicocientíficos, militares e de divulgação histórica, no período compreendido entre 1945 e 2015, ou seja, das primeiras publicações sobre a guerra desde seu final até os dias atuais.

Ao se fazer a análise dessa produção, estar-se-á problematizando as crenças comuns acima descritas. Será demonstrado que, quantitativamente, a produção sobre a participação do país na guerra é muito mais expressiva do que se costuma acreditar; serão discutidas também as tendências historicamente verificáveis de temas e abordagens historiográficas, bem como o interesse geral sobre tal participação, ao longo de mais de setenta anos.

Inicialmente serão abordados os problemas metodológicos do levantamento, os critérios de seleção das publicações, de exclusão de títulos e a escolha dos eixos temáticos. A seguir será realizada uma primeira análise, de caráter mais quantitativo, sobre tal produção. As tendências da produção bibliográfica, ao longo do tempo, serão examinadas. Em seguida, com base nessas estatísticas, serão discutidas as razões por que alguns tópicos são mais abordados que outros, em determinados períodos, a que tipo de autores e de público são direcionadas tais produções e os focos de interesse de autores e do público civil e militar. A análise será concluída com um exame dos problemas práticos que interferem direta ou indiretamente na produção, como o papel das instituições militares e universitárias na definição dos temas e das abordagens, o papel limitador dos acervos relacionados ao tema, as modas historiográficas e sua influência, na abertura de novas abordagens e fontes documentais, assim como as demandas editoriais e acadêmico-científicas.

A conclusão desse ensaio é que as histórias da participação brasileira na Segunda Guerra Mundial estão muito longe de constituírem um campo restrito e pouco abordado da historiografia brasileira. De fato, em décadas passadas o envolvimento do país no conflito despertava interesse menor de pesquisadores e de público, em comparação com outros temas da história brasileira do período republicano. Contudo, nas últimas três décadas houve, tanto quantitativa quanto qualitativamente, uma notável expansão, com o envolvimento de um número maior e da mais diversa origem de pesquisadores civis e militares, uma ampliação dos temas e, por fim mas não menos importante, uma maior complexidade das abordagens, com questionamentos sobre temas e interpretações clássicas e revisões vigorosas, baseadas em documentação pouco ou nunca antes acessada. Há, portanto, um imenso espaço a ser ocupado e explorado pelos pesquisadores civis e militares, com vantagens recíprocas.

\section{Sobre o levantamento bibliográfico}

Apenas dois levantamentos sobre a bibliografia da participação 
brasileira na guerra foram realizados de modo sistemático e publicados. Ambos concentraram-se, porém, na história da Força Expedicionária Brasileira e do Grupo de Caça da Força Aérea Brasileira. O primeiro estudo desse tipo foi o livro do coronel do Exército Francisco Ruas Santos, Fontes para a História da FEB, publicado em 1958 pela Biblioteca do Exército Editora ${ }^{1}$. O autor, veterano da FEB, fez um levantamento exaustivo do material disponível até o final da década de 1950, com breves comentários sobre uma parte dos títulos, que considerava mais importantes. Além das publicações, Ruas Santos também arrolou e comentou as fontes documentais então disponíveis, tanto escritas quanto sonoras e visuais. É, sem dúvida, um clássico, não apenas pelo ineditismo da obra, mas sobretudo pela qualidade do levantamento e dos comentários. É uma obra que se distancia da autolouvação que caracterizava parte da produção sobre a FEB, abrindo espaço para uma autocrítica institucional rara nas Forças Armadas brasileiras de sua época. Dos assuntos fora do âmbito da FEB, contudo, somente algumas publicações sobre a entrada do país na guerra foram abordadas.

O segundo levantamento bibliográfico, de autoria do coronel do Exército Ney Eischler Cardoso ${ }^{2}$, foi realizado mais de uma década depois. $\mathrm{O}$ artigo, A FEB e a História Militar, foi o resultado desse levantamento. Publicado primeiramente na Revista A Defesa Nacional, de Julho-Agosto de 1971, foi reeditado, em 1973, na Revista de História da Universidade de São Paulo . O artigo consistiu em um breve comentário geral e no simples arrolamento de 162 títulos. Seu foco, como o próprio título esclarece, foi a FEB, havendo ainda algumas referências a obras sobre o envolvimento diplomático do Brasil na guerrra, o que fazia sentido naquele momento dos estudos de história militar, às vezes confundida como parte da história das relações internacionais.

Um outro levantamento, que não é bibliográfico, mas temático, foi útil para este trabalho: trata-se dos resultados de artigo, publicado em 2010, sobre como a participação brasileira na Segunda Guerra apareceu nos manuais didáticos brasileiros desde 1945 até o final da década de $1990^{3}$. Usando-se abordagens quantitativas e qualitativas, foram verificadas tendências de construção de narrativas que variavam conforme as lutas pelo significado daquela participação colocavam em choque divergentes concepções de ação política e de participação das Forças Armadas nas relações de poder. Isso era evidenciado não somente no destaque decrescente dado ao tema nos livros didáticos (de capítulos/subcapítulos inteiros, nas décadas de 1940 e 1950, para poucas linhas, no final da década de 1990) mas também na forma como o assunto era abordado. Os textos, mais descritivos que analíticos, das décadas de 1940, 1950 e 1960, focados nas ações dos expedicionários e nas vitórias militares das Forças Armadas brasileiras cederam progressivamente espaço para questionamentos políticos, tais como a contradição de enfrentar na Europa o nazifascismo e vivenciar um regime semelhante no Brasil; as consequências 
políticas de tal participação; e, já nas décadas de 1980 e 1990, as considerações sobre a mobilização do front doméstico e suas consequências para as classes trabalhadoras. Assim, do estudo sobre a produção didática foi aproveitado, para este artigo, a inter-relação entre as duas dimensões da análise da produção bibliográfica; a saber, a abordagem que analisa, estatisticamente, o que foi publicado sobre o tema e aquela que se detém mais nos conteúdos das obras.

\section{Projeto "Força Expedicionária Brasileira: história e historiografia"}

Definidas essas questões, foi desenvolvido o projeto de pesquisa "Força Expedicionária Brasileira, história e historiografia", cujos objetivos são, além da confecção deste artigo, publicar um Guia Bibliográfico sobre a participação brasileira no conflito, e manter um levantamento atualizado das publicações em homepage própria ${ }^{4}$. Ficou claro, desde o início, que esse levantamento deveria ampliar o alcance da pesquisa para a participação brasileira na guerra como um todo, inclusive o front interno, e abordar outras dimensões da vida social, como o cotidiano, a cultura, as formas de construção de memória e patrimônio material, etc.

Como objeto de inclusão nesse levantamento, a publicação deve ser integralmente relacionada à participação do país no conflito ou, no caso de não ser voltada especificamente para a participação na guerra, conter informações e/ ou análises relevantes para o assunto. Um exemplo da utilização desse critério é a obra "Meio Século de Combate - diálogo com Cordeiro de Farias, Aspásia Camargo e Walder de Goes" 5 . Trata-se da edição do depoimento oral prestado pelo General Cordeiro de Farias, que foi Comandante da Artilharia da FEB e participante importante da política brasileira, desde a década de 1920 até seu falecimento em 1981. Não é, portanto, um livro especificamente dedicado ao tema. A parte do livro referente à Segunda Guerra Mundial compõe pouco mais de um quinto do conteúdo total, mas é de suma relevância para vários tipos de estudos sobre o tema do Brasil no conflito. Tal importância garante ao livro sua inclusão no levantamento efetuado.

A metodologia da pesquisa implicou a pesquisa bibliográfica em arquivos, em sistemas de localização bibliográfica de bibliotecas reais e virtuais e no auxílio de pesquisadores do tema no Brasil e no exterior, aos quais o autor é grato pela imensa colaboração.

O primeiro desafio desse projeto foi definir os critérios de seleção do que seria incluído no repertório bibliográfico e o que não seria. A escolha, baseada no princípio de que as obras arroladas devem possuir autoria definida, edição e distribuição maior que meros grupos de memória, inclui artigos de periódicos científicos e de divulgação científica, periódicos profissionais militares, livros autorais, coletâneas, capítulos de livros, trabalhos de conclusão acadêmicos (teses de doutorado e livre-docência, dissertações de mestrado, monografias 
selecionadas) e trabalhos completos publicados em anais de eventos científicos. Artigos de jornais diários e revistas voltados para o público em geral não foram incluídos nessa pesquisa, pois requeririam levantamento tão exaustivo, em todo o território nacional, que inviabilizaria o término do projeto de pesquisa, a despeito da qualidade e dimensões de alguns desses artigos constituírem contribuições relevantes.

Para a mensuração estatística, um problema logo surgiu: como fazer a contagem de uma coletânea, com vários capítulos? Como o objetivo é compreender o desenvolvimento da produção bibliográfica, tanto por ocorrência de publicações gerais, quanto por temas, ao longo de sete décadas, optou-se por contar a coletânea como uma publicação per si, e cada capítulo individualmente também como uma publicação. Esse procedimento é justificado pelo fato de que a organização de uma coletânea indica uma abordagem mais ampla, com mais assuntos, o que já configura uma opção editorial clara no tratamento do tema da participação do país na guerra. E cada capítulo/contribuição da obra coletiva implica um direcionamento temático que deve ser levado em consideração e ser, portanto, mensurável.

Após a última inserção de dados em março de 2016, levantaram-se 1092 publicações, sendo 395 livros (dos quais 18 coletâneas), 99 capítulos de livros, 107 artigos em periódicos científicos, 345 artigos em periódicos profissionais militares, 35 artigos em periódicos de divulgação histórica, 71 teses e dissertações acadêmicas, e 40 trabalhos completos publicados em anais de eventos científicos. Obviamente, haverá ausência de alguns títulos, mas entende-se que, para a confecção deste artigo, a base documental é suficiente para a análise.

Após o exame inicial da bibliografia coletada, procurou-se escolher os eixos temáticos. Eles deveriam abranger os mais variados assuntos relativos ao tema. Apesar de várias publicações poderem ser colocadas em mais de uma categoria, optou-se pela inclusão única, para que se pudesse examinar melhor o desenvolvimento da historiografia sobre o tema geral. Assim, foram determinados inicialmente doze eixos temáticos: a) Obras gerais; b) Entrada do Brasil na Segunda Guerra Mundial; Relações Internacionais; c) Guerra no Atlântico Sul; d) Front Interno; Cotidiano; Bases no Norte/Nordeste; Batalha da Borracha; e) FEB/FAB: Campanha da Itália; Análises gerais e acadêmicas; f) FEB/FAB: Campanha da Itália; unidades combatentes e de apoio; g) FEB/FAB: Campanha da Itália; Memórias de ex-combatentes; h) FEB/FAB: Campanha da Itália; Correspondentes de guerra; i) Expressões culturais contemporâneas e posteriores ao envolvimento na Segunda Guerra Mundial; j) Papel político e consequências da participação brasileira na guerra; k) Reintegração dos expedicionários à sociedade; 1) Estudos sobre memória e patrimônio.

Para aprimorar a análise, esses doze eixos foram agrupados em blocos 
temáticos, facultando-se, assim, uma análise comparativa mais geral entre os diversos conjuntos de publicações. Os blocos temáticos foram: I) Obras Gerais; II) Relações internacionais e entrada do Brasil na Guerra; III) Front Interno; IV) Campanha da Itália; V) Expressões Culturais; VI) Pós-guerra.

Para a análise, também foi efetuada a separação entre as publicações voltadas para o público geral e aquelas que, mais pela divulgação e distribuição limitadas do que pelo conteúdo em si, foram direcionadas para o público profissional militar. De maneira análoga foi feita uma distinção entre editoras civis e militares, de modo a procurar entender os critérios de publicação desses grupos tão distintos, ao longo do tempo.

Deve-se advertir o leitor de que a análise aqui realizada não inclui a apreciação individualizada das obras e sua contribuição para o "estado da arte" de cada eixo temático. O debate de cada tópico requeriria um imenso espaço, inviável para as dimensões de um único artigo. A análise aqui realizada consistirá na discussão de linhas gerais da produção historiográfica e seu desenvolvimento, sem entrar em detalhes sobre a qualidade das obras individualmente. Uma discussão dessa natureza exigiria artigos específicos para cada eixo temático, ou mesmo para cada tópico. A constatação da variedade de contribuições e posições opostas ou complementares mostra muito bem que a produção bibliográfica sobre a participação brasileira na Segunda Guerra Mundial é muito maior, mais variada e mais rica do que se imagina.

\section{Números absolutos: analisando-se os dados}

Procurou-se, inicialmente, compreender a evolução das publicações sobre o tema, ao longo dos anos. Graficamente, o resultado foi o seguinte:

Figura 1 - Publicações ao longo do período 1945-2015

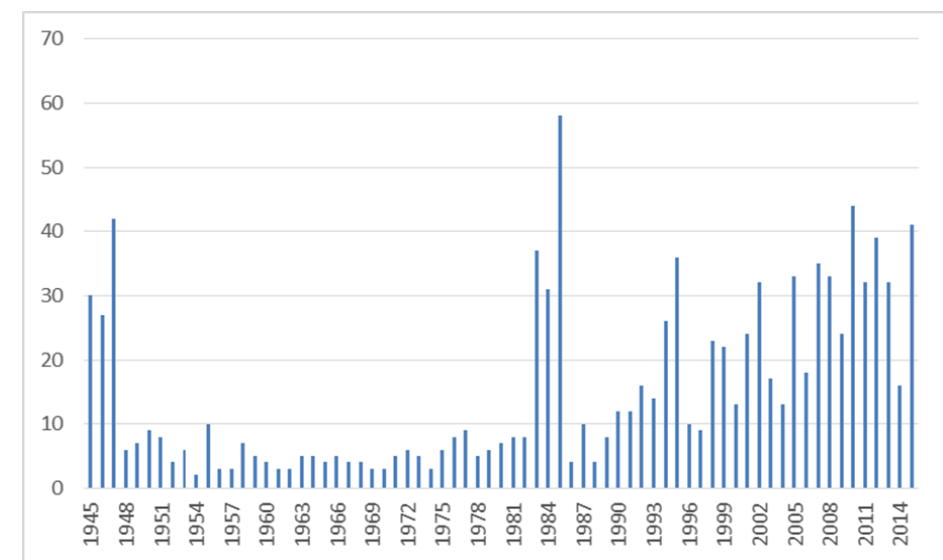

Fonte: Levantamento da Produção Bibliográfica sobre a Participação do Brasil na Segunda Guerra Mundial. Projeto de Pesquisa "Força Expedicionária Brasileira: história e

historiografia", CNPq-Universidade Estadual de Londrina, 2010-2015. 
Percebe-se que há alguns picos de produção e períodos em que o ritmo de publicação se estabiliza em níveis baixos de novas obras. O primeiro pico de publicações se deu logo após o fim da guerra, o que é natural, dado o impacto imediato na vida das quatro dezenas de milhões de pessoas no Brasil de meados da década de 1940. A partir de 1948 há um ritmo relativamente baixo de produção, até o início da década de 1980 (269 títulos em 35 anos, média de 7,68 títulos publicados por ano). Entre os anos 1983 e 1985 foram publicados 126 títulos, numa média impressionante de 42 títulos por ano. Nos anos seguintes, os níveis baixaram novamente, mas pode-se notar, a partir da década de 1990, uma tendência média crescente (626 títulos em 26 anos, média de 24,07 títulos publicados por ano), coincidindo os picos, na maior parte das vezes, com os aniversários decenais da participação brasileira na guerra e do fim desta.

Alguns picos, no entanto, devem ser explicados à parte. É o caso do período 1983-1985. O centenário do nascimento do Comandante da FEB, Marechal Mascarenhas de Moraes, em 1983, deu ensejo a uma volumosa edição comemorativa da Revista do Exército Brasileiro, com nada menos de 28 artigos sobre diversos aspectos do comando do "aniversariante" e das unidades da FEB, em tom predominantemente laudatório. Se fosse excluída tal "distorção" estatística, o número de publicações seria semelhante ao dos anos anteriores. Já, nos dois anos seguintes, que completavam trinta anos do envio dos expedicionários na Itália (1984) e o fim da guerra (1985), houve uma produção sólida, tanto nos meios civis quanto nos militares, e expressiva quantitativamente (89 títulos).

A partir do final da década de 1990, a produção bibliográfica já não depende tanto das efemérides da guerra para seu crescimento. Os anos-chave de final 04 e 05 continuam sendo anos de produção expressiva, mas esta aumentou em outros momentos, como em 2010. O mais importante, porém, não são os picos, mas uma média consistente de produção: somente nos últimos dez anos (2006-2015) foram publicados 314 títulos - 29\% de toda a produção em 70 anos. A produção é crescente, especialmente em livros, coletâneas e em artigos de periódicos científicos para o público de perfil mais "civil”, ou seja, não-profissional militar.

O segundo problema investigado consistiu em verificar quais foram as áreas temáticas mais publicadas, no período entre 1945 e 2015. Os resultados foram os seguintes:

Tabela 1 - Áreas temáticas mais publicadas no período 1945-2015

\begin{tabular}{|l|c|c|}
\hline Área Temática & $\begin{array}{l}\text { Publicações } \\
\text { ( N ú m e r o s } \\
\text { absolutos) }\end{array}$ & Proporção (\%) \\
\hline $\begin{array}{l}\text { a) Obras gerais } \\
\text { b) Entrada do Brasil na Segunda Guerra Mundial; Relações } \\
\text { Internacionais }\end{array}$ & 99 & 2,47 \\
\hline c) Guerra no Atlántico Sul & 46 & 9,07 \\
\hline
\end{tabular}




\begin{tabular}{|c|c|c|}
\hline $\begin{array}{l}\text { d) Front Interno; Cotidiano; Bases no Norte/Nordeste; Batalha } \\
\text { da Borracha }\end{array}$ & 120 & 10,99 \\
\hline e) EEBLEAB: Campanha da ltália: Análises gerais e acadêmicas & 243 & 22,25 \\
\hline 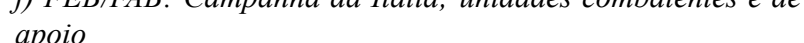 & & \\
\hline a) FEB/FAB: Campanha da Itália: Memórias de ex-combatentes & 206 & 18 \\
\hline $\begin{array}{l}\text { h) EEBLAB: Campanha da ltália: Correspondentes de guerra } \\
\text { i) Expressós culturais contemporaneas e posteriores ao a }\end{array}$ & 57 & 22 \\
\hline na Segunda Guerra Mundial & & \\
\hline j) Papel politico e consequencias da participação brasileira na & 25 & 2,29 \\
\hline 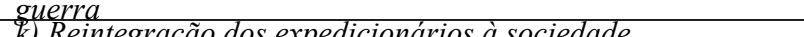 & 23 & \\
\hline 1) Estudos sobre memoria e patrimonio & $\frac{48}{1092}$ & $\frac{4.40}{100 \%}$ \\
\hline
\end{tabular}

Fonte: Levantamento da Produção Bibliográfica sobre a Participação do Brasil na Segunda Guerra Mundial. Projeto de Pesquisa "Força Expedicionária Brasileira: história e historiografia", CNPqUniversidade Estadual de Londrina, 2010-2015.

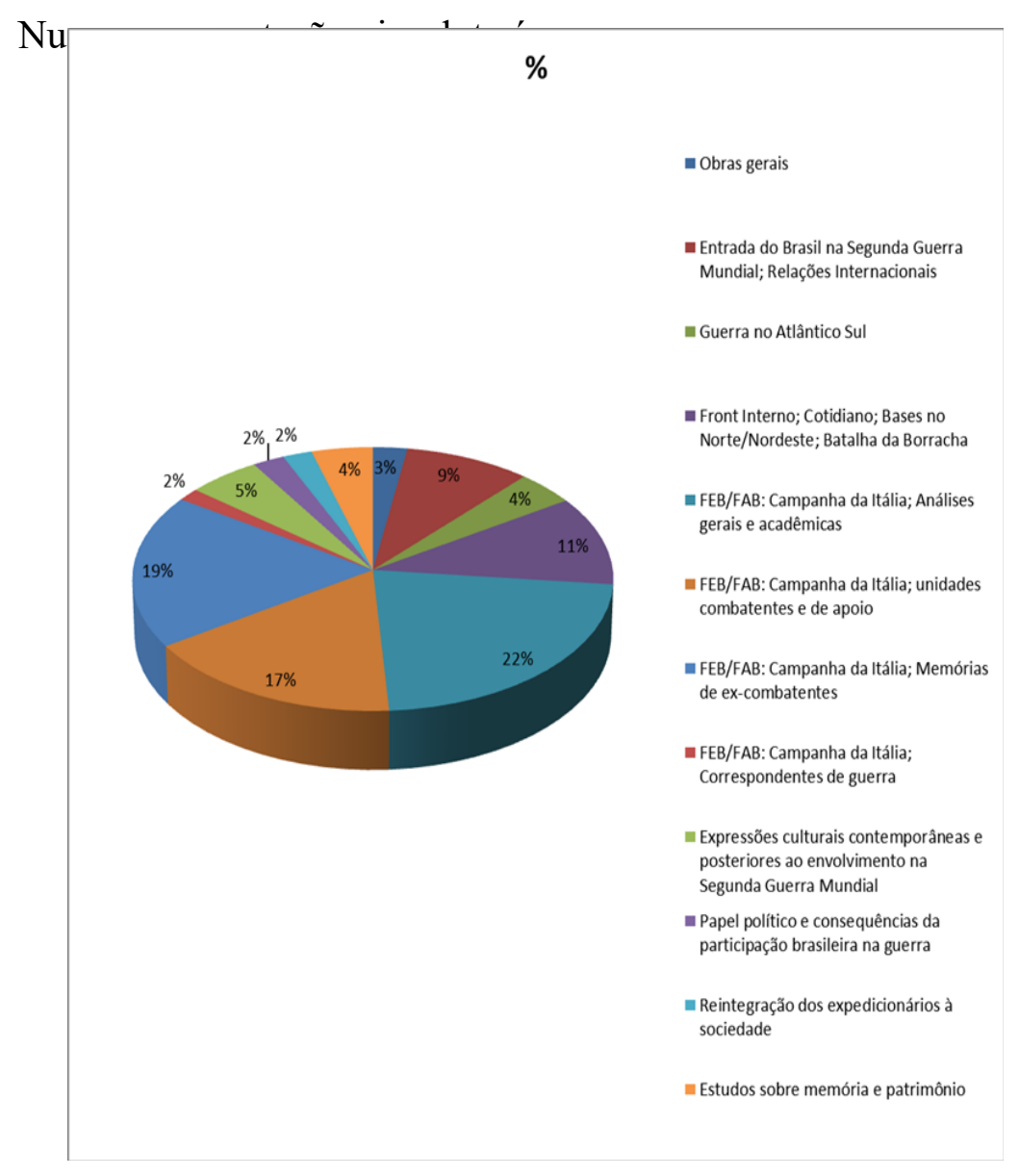

Fonte: Levantamento da Produção Bibliográfica sobre a Participação do Brasil na Segunda Guerra Mundial. Projeto de Pesquisa "Força Expedicionária Brasileira: história e historiografia", CNPqUniversidade Estadual de Londrina, 2010-2015. 
Aglutinando as áreas em blocos temáticos temos os seguintes resultados:

Tabela 2 - Blocos Temáticos mais publicados no período 1945-2015

\begin{tabular}{|l|c|c|}
\hline Bloco Temático & $\begin{array}{l}\text { Publicações } \\
\text { (Números absolutos) }\end{array}$ & Proporção (\%) \\
\hline Obras Gerais & 27 & 2,47 \\
\hline $\begin{array}{l}\text { Relaçôes internacionais e entrada do Brasil na } \\
\text { Guerra }\end{array}$ & 145 & 13,28 \\
\hline Front lnterno & 120 & 10,99 \\
\hline Campanha da Itália & 647 & 59.24 \\
\hline Expressôes Culturais & 57 & 5,22 \\
\hline Pos-guerra & 96 & 80 \\
\hline TOTAL & 1092 & $100 \%$ \\
\hline
\end{tabular}

Fonte: Levantamento da Produção Bibliográfica sobre a Participação do Brasil na Segunda Guerra Mundial. Projeto de Pesquisa "Força Expedicionária Brasileira: história e historiografia", CNPqUniversidade Estadual de Londrina, 2010-2015.

Numa representação visual, teríamos:

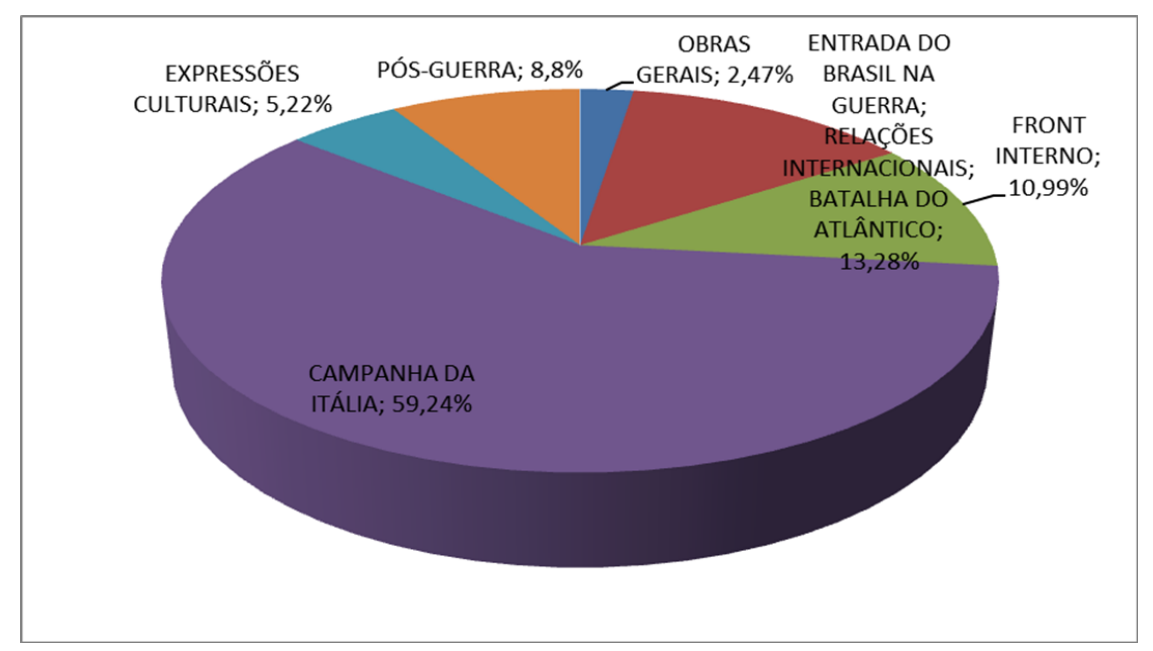

nte: Levantamento da Produção Bibliográfica sobre a Participação do Brasil na Segunda Guerra Mundial. Projeto de Pesquisa "Força Expedicionária Brasileira: história e historiografia", CNPqUniversidade Estadual de Londrina, 2010-2015.

Por mais que a historiografia sobre a participação na guerra tenha ampliado os campos de estudo, o tema da Campanha da Itália predomina nas publicações de todo o período, com 59,24\% dos títulos. A seguir, com números bem mais modestos, estão as Relações Internacionais (13,28\%), que compreendem as questões diplomáticas e todo o contexto específico da guerra no litoral brasileiro, responsável pela declaração de beligerância e pelo envolvimento definitivo do país no conflito; em terceiro lugar, os estudos sobre o front interno $(10,99 \%)$, que incluem abordagens sobre a mobilização econômica, a vida cotidiana nas cidades do país, as relações entre a população brasileira e as minorias de "súditos do Eixo" e, por fim mas não menos importante, a "Batalha da Borracha", um dos episódios menos conhecidos da história brasileira da década de 1940 . 
Se, em números brutos, a produção é predominantemente voltada para o que poderíamos chamar de temas tradicionais da história militar, o exame da concentração temática, ao longo do tempo, pode oferecer indícios seguros sobre a "história da historiografia" da participação brasileira no conflito. Assim, para examinar o desenvolvimento de cada área temática ao longo do tempo, divide-se a análise por períodos de dez anos, a contar de 1945. Em primeiro lugar, procura-se saber o quanto foi publicado sobre o tema em cada década. ${ }^{6}$

Tabela 3a - Publicações por tema e por década

\begin{tabular}{|c|c|c|c|c|c|c|c|c|c|}
\hline & $\begin{array}{l}1945 \\
\mathrm{a} \\
1955 \\
\end{array}$ & $\begin{array}{l}1956 \\
a \\
1965 \\
\end{array}$ & $\begin{array}{l}1966 \\
a \\
1975\end{array}$ & $\begin{array}{l}1976 \\
\text { a } \\
1985\end{array}$ & $\begin{array}{l}1986 \\
\text { a } \\
1995\end{array}$ & $\begin{array}{l}1996 \\
\text { a } \\
2005\end{array}$ & $\begin{array}{l}2006 \\
\text { a } \\
2015\end{array}$ & $\mathrm{~s} / \mathrm{d}$ & Total \\
\hline Obras gerais & 02 & 02 & 01 & 02 & 09 & 05 & 06 & 0 & 27 \\
\hline $\begin{array}{l}\text { Entrada do Brasil } \\
\text { na Segunda } \\
\text { Guerra Mundial; } \\
\text { Relações } \\
\text { Internacionais }\end{array}$ & 0 & 0 & 02 & 20 & 12 & 15 & 50 & 0 & 99 \\
\hline $\begin{array}{l}\text { Guerra no } \\
\text { Atlântico Sul }\end{array}$ & 0 & 01 & 05 & 10 & 8 & 9 & 12 & 01 & 46 \\
\hline $\begin{array}{l}\text { Front Interno; } \\
\text { Cotidiano; } \\
\text { Bases no Norte/ } \\
\text { Nordeste; Batalha } \\
\text { da Borracha }\end{array}$ & 01 & 0 & 01 & 03 & 20 & 35 & 60 & 0 & 120 \\
\hline $\begin{array}{l}\text { FEB/FAB: } \\
\text { Campanha da } \\
\text { Itália; Análises } \\
\text { gerais e } \\
\text { acadêmicas }\end{array}$ & 61 & 10 & 18 & 24 & 32 & 35 & 58 & 05 & 243 \\
\hline $\begin{array}{l}\text { FEB/FAB: } \\
\text { Campanha da } \\
\text { Itália; unidades } \\
\text { combatentes e de } \\
\text { apoio }\end{array}$ & 50 & 09 & 08 & 43 & 18 & 17 & 33 & 03 & 181 \\
\hline $\begin{array}{l}\text { FEB/FAB: } \\
\text { Campanha } \\
\text { da Itália; } \\
\text { Memórias de ex- } \\
\text { combatentes }\end{array}$ & 35 & 09 & 07 & 58 & 25 & 50 & 17 & 05 & 206 \\
\hline $\begin{array}{l}\text { FEB/FAB: } \\
\text { Campanha } \\
\text { da Itália; } \\
\text { orrespondentes } \\
\text { de guerra }\end{array}$ & 06 & 0 & 0 & 02 & 02 & 02 & 04 & 01 & 17 \\
\hline $\begin{array}{l}\text { Expressões } \\
\text { culturais } \\
\text { contemporâneas } \\
\text { e posteriores ao } \\
\text { envolvimento na } \\
\text { Segunda Guerra } \\
\text { Mundial }\end{array}$ & 03 & 04 & 01 & 05 & 08 & 08 & 27 & 01 & 57 \\
\hline $\begin{array}{l}\text { Papel político e } \\
\text { consequências } \\
\text { da participação } \\
\text { brasileira na } \\
\text { guerra }\end{array}$ & 0 & 01 & 0 & 05 & 04 & 07 & 08 & 0 & 25 \\
\hline $\begin{array}{l}\text { Reintegração dos } \\
\text { expedicionários à } \\
\text { sociedade }\end{array}$ & 0 & 03 & 0 & 02 & 0 & 04 & 13 & 01 & 23 \\
\hline $\begin{array}{l}\text { Estudos sobre } \\
\text { memória e } \\
\text { patrimônio }\end{array}$ & 01 & 03 & 01 & 03 & 05 & 09 & 26 & 0 & 48 \\
\hline
\end{tabular}




\begin{tabular}{|l|l|l|l|l|l|l|l|l|l|}
\hline TOTAL & 159 & 42 & 44 & 177 & 143 & 196 & 314 & 17 & 1092 \\
\hline
\end{tabular}

Fonte: Levantamento da Produção Bibliográfica sobre a Participação do Brasil na Segunda Guerra Mundial. Projeto de Pesquisa "Força Expedicionária Brasileira: história e historiografia", CNPqUniversidade Estadual de Londrina, 2010-2015.

Tabela 3b - Publicações por bloco temático por década

\begin{tabular}{|c|c|c|c|c|c|c|c|c|c|}
\hline & $\begin{array}{l}1945 \\
\text { a } \\
1955\end{array}$ & $\begin{array}{l}1956 \\
a \\
1965\end{array}$ & $\begin{array}{l}1966 \\
a \\
1975\end{array}$ & $\begin{array}{l}1976 \\
a \\
1985\end{array}$ & $\begin{array}{l}1986 \\
a \\
1995\end{array}$ & $\begin{array}{l}1996 \\
\text { a } \\
2005\end{array}$ & $\begin{array}{l}2006 \\
\text { a } \\
2015\end{array}$ & $\mathbf{s} / \mathbf{d}$ & Total \\
\hline Obras gerais & 02 & 02 & 01 & 02 & 09 & 05 & 06 & 0 & 27 \\
\hline $\begin{array}{l}\text { Relações internacionais e } \\
\text { entrada do Brasil na Guerra }\end{array}$ & 0 & 01 & 07 & 30 & 20 & 24 & 62 & 01 & 145 \\
\hline Front Interno & 01 & 0 & 01 & 03 & 20 & 35 & 60 & 0 & 120 \\
\hline Campanha da Itália & 152 & 28 & 33 & 127 & 77 & 104 & 112 & 14 & 647 \\
\hline Expressös Culturais & 03 & 04 & 01 & 05 & 08 & 08 & & 01 & 57 \\
\hline Pos-guerra & 01 & 07 & 01 & 10 & 09 & 20 & 47 & 01 & 96 \\
\hline TOTA & 159 & 42 & 44 & 177 & 143 & 196 & 314 & 17 & 1092 \\
\hline
\end{tabular}

Fonte: Levantamento da Produção Bibliográfica sobre a Participação do Brasil na Segunda Guerra Mundial. Projeto de Pesquisa "Força Expedicionária Brasileira: história e historiografia", CNPqUniversidade Estadual de Londrina, 2010-2015.

O tema das relações internacionais e das ações de guerra no Atlântico Sul apresentou produção muito reduzida nas primeiras três décadas após o fim do conflito. Houve um crescimento significativo somente a partir de meados dos anos 1970, e uma vigorosa produção na última década (2006-2015), impulsionada principalmente pelas publicações sobre os torpedeamentos e a Guerra no Atlântico Sul.

Fenômeno semelhante ocorreu com a produção bibliográfica sobre o tema do Front Interno. Por quatro décadas, esse tema foi praticamente ignorado pelos autores que publicavam sobre a guerra no Brasil. Nas últimas três décadas, porém, houve um salto quantitativo tão expressivo que, na década mais recente (2016-2015), foi o tema que, isoladamente, reuniu mais publicações $(19,10 \%)$, seguido de perto pelas análises gerais e acadêmicas sobre a campanha da Itália $(18,47 \%)$. Quando se reúnem, porém, os temas por eixos temáticos, a Campanha da Itália, em todas as suas dimensões, é a mais publicada em todos os cortes decenais.

Ainda em relação ao tema do front interno, nada menos que a metade da produção bibliográfica se concentra nos estudos do cotidiano de cidades e regiões, durante a guerra, e pouco mais de um quarto das publicações $(26,66 \%)$ nos estudos sobre comunidades de súditos ou descendentes do Eixo, durante a guerra, especialmente nos estados do sul do país. Trata-se de uma subárea de estudos em franco crescimento.

Quando se analisa a produção bibliográfica sobre as diversas dimensões da Campanha da Itália, notam-se algumas diferenças. No caso de estudos de unidades combatentes e de apoio, por natureza mais específicos, verificam-se três picos. O primeiro foi no imediato pós-guerra, impulsionado por períodicos profissionais militares e relatos de oficiais das unidades na forma de livros. O 
segundo pico da produção foi em 1983, para o qual contribuiu decisivamente o número especial, já comentado neste artigo, do centenário do Marechal Mascarenhas de Morais - uma parte dos artigos consistiu na memória das relações do Comandante da FEB com as diferentes unidades. Por fim, o terceiro pico se deu na década 2006-2015, com grande volume de trabalhos sobre os serviços de saúde da FEB, o que incluiu o serviço médico, psiquiátrico e a enfermagem.

Já, no caso das memórias de guerra, escritas pelos próprios combatentes ou por terceiros (geralmente familiares, jornalistas ou pesquisadores), houve um impulso inicial de publicação logo após a guerra, um período de duas décadas de poucas publicações e uma retomada, a partir da segunda metade da década de 1970, com o pico na década de 1996-2005. Sobre esse "boom" de publicação de memórias de ex-combatentes, deve-se notar que, além das iniciativas individuais de expedicionários septuagenários e suas famílias para deixar inscrita suas memórias de guerra, foi também o momento de franco crescimento de abordagens, na historiografia universitária, dos estudos de história oral e memória. Essa combinação mostrou-se muito profícua na quantidade e qualidade das publicações.

O tema da memória repercutiu também em dois outros temas, ligados às formas de representação do passado: as expressões culturais, coetâneas ou posteriores à participação do país na guerra; e os estudos sobre memória e patrimônio. Ambos tiveram um significativo aumento de produção na última década, principalmente por autores de extração universitária.

Por fim, as questões vinculadas ao pós-guerra, como as consequências políticas e o problema da reintegração social dos veteranos de guerra tiveram evoluções distintas. No primeiro caso, a obra "inaugural" do tema na historiografia, "As Duas Guerras da FEB", de Joel Silveira, foi publicada em 1965, estimulada pela ascensão de um grupo de oficiais que havia pertencido à FEB e, naquele momento, estava à testa do regime militar. Mas o tema foi pouco tocado na década de 1970; o crescimento do tema na historiografia se deu a partir do fim do regime militar, com obras que questionam a versão de que o retorno da FEB contribuiu para a derrubada do Estado Novo. Já, no caso da desmobilização dos expedicionários e sua reintegração social, o tema foi inicialmente trabalhado por jornalistas e lideranças de associações de excombatentes, mas não constava da produção bibliográfica. Seu primeiro estudo sistemático foi o artigo de João Felipe Sampaio Barbosa, em 1985. ${ }^{7}$ A temática voltou à tona a partir de 2003 e está em crescimento.

Um fator importante a ser considerado é se a produção e distribuição estão voltadas para um público geral ou para um público profissional militar. Com efeito, nem todas as publicações foram endereçadas ao público geral, ficando uma parte delas mais restrita aos profissionais militares. Não se trata de censura ou exclusão de obras militares direcionadas ao público geral, mas, 
excetuando-se os estudiosos do tema, existem publicações em periódicos profissionais que alcançam muito pouco o público não-militar. Assim, se não fosse efetuada uma tabulação levando-se em consideração esse fator, teríamos resultados enganosos em relação tanto à autoria quanto em relação ao público leitor da produção bibliográfica estudada. Para esse estudo definiram-se como publicaçações destinadas ao público profissional militar as revistas editadas pela instituição militar ou por seus membros-A Defesa Nacional, Revista Militar Brasileira, Revista do Exército Brasileiro, Navigator, Revista do Instituto de Geografia e História Militar do Brasil, Revista do Clube Militar, Revista do Clube Naval, Military Review - Edição brasileira, Mensário de Cultura Militar, The Professional Bulletin of Army History (EUA) - e publicações de órgãos vinculados às Forças Armadas brasileiras e estadunidenses - Secretaria Geral do Ministério da Guerra, Serviço de Documentação Geral da Marinha, Diretoria do Patrimônio Histórico e Documentação da Marinha, Instituto Histórico-Cultural da Aeronáutica, Gabinete Fotocartográfico do Exército, Mediterranean Teather of Operations/Unites States Army, United States Center of Military History.

Não foram consideradas, como publicações voltadas prioritariamente para os profissionais militares, as obras editadas pela Biblioteca do Exército Editora (Bibliex) e a Revista $A$ Nação Armada. As obras da Bibliex possuem distribuição nacional e atingem o público civil, como a maior parte das editoras comerciais do país; a revista $A$ Nação Armada, embora tivesse um corpo editorial predominantemente militar, era mantida por assinaturas do público em geral e por anúncios publicitários.

Estabelecidos esses critérios, o levantamento computou 747 publicações voltadas para o público geral (68,4\% do total) e 345 publicações voltadas para o público profissional militar (31,6\% do total), ou seja, um pouco mais de $2 / 3$ da produção bibliográfica foi endereçada ao público geral e pouco menos de $1 / 3$ ao público mais especificamente militar. A distribuição dessas publicações, por assunto e por décadas, está assim estabelecida:

Tabela 4 - áreas mais publicadas - público geral/público profissional militar

\begin{tabular}{|c|c|c|c|c|c|c|c|c|c|}
\hline & $\begin{array}{r}1945 \\
- \\
1955\end{array}$ & $\begin{array}{r}1956 \\
- \\
1965 \\
\end{array}$ & $\begin{array}{r}1966 \\
- \\
1975 \\
\end{array}$ & $\begin{array}{r}1976 \\
- \\
1985 \\
\end{array}$ & $\begin{array}{r}1986 \\
- \\
1995 \\
\end{array}$ & $\begin{array}{r}1996 \\
- \\
2005 \\
\end{array}$ & $\begin{array}{r}2006 \\
- \\
2015 \\
\end{array}$ & $\mathbf{s} / \mathbf{d}$ & Total \\
\hline Obras gerais - Geral & 02 & 02 & 00 & 00 & 02 & 02 & 04 & 00 & 12 \\
\hline Obras gerais-Militar & $\frac{00}{02}$ & $\frac{00}{02}$ & of & $\frac{02}{02}$ & $\frac{07}{09}$ & $\frac{03}{05}$ & $\frac{02}{06}$ & 00 & $\frac{15}{77}$ \\
\hline Entrada do Brasil na Segunda & 00 & 00 & 02 & 18 & $\frac{18}{12}$ & 15 & $\frac{10}{48}$ & 00 & -95 \\
\hline Mundial; & & & & & & & & & \\
\hline Internacionais - Geral & 00 & & 0 & 2 & & & & 0 & \\
\hline Entrada do Brasil na Segunda & 00 & 00 & 00 & 02 & 00 & 00 & 02 & 00 & 04 \\
\hline Internacionais - Militar & & & & & & & & & \\
\hline Entrada do Brasil na Segunda & 00 & 00 & 00 & 20 & 12 & 15 & 50 & 00 & 99 \\
\hline Guerra Mundial; Relações & & & & & & & & & \\
\hline Internacionais - Total & & & & & & & & & \\
\hline Guerra no At ầntico Su -Geral & $\frac{00}{00}$ & 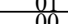 & 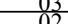 & $\frac{12}{08}$ & 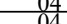 & $\frac{04}{05}$ & 08 & of & 23 \\
\hline $\begin{array}{l}\text { Guerra no Atlantico Sul -Militar } \\
\text { Guerra no Atlântico Sul-Total }\end{array}$ & $\frac{00}{00}$ & 00 & $\frac{02}{05}$ & $\frac{00}{10}$ & 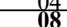 & $\frac{5}{09}$ & $\frac{04}{12}$ & 00 & $\frac{23}{46}$ \\
\hline
\end{tabular}




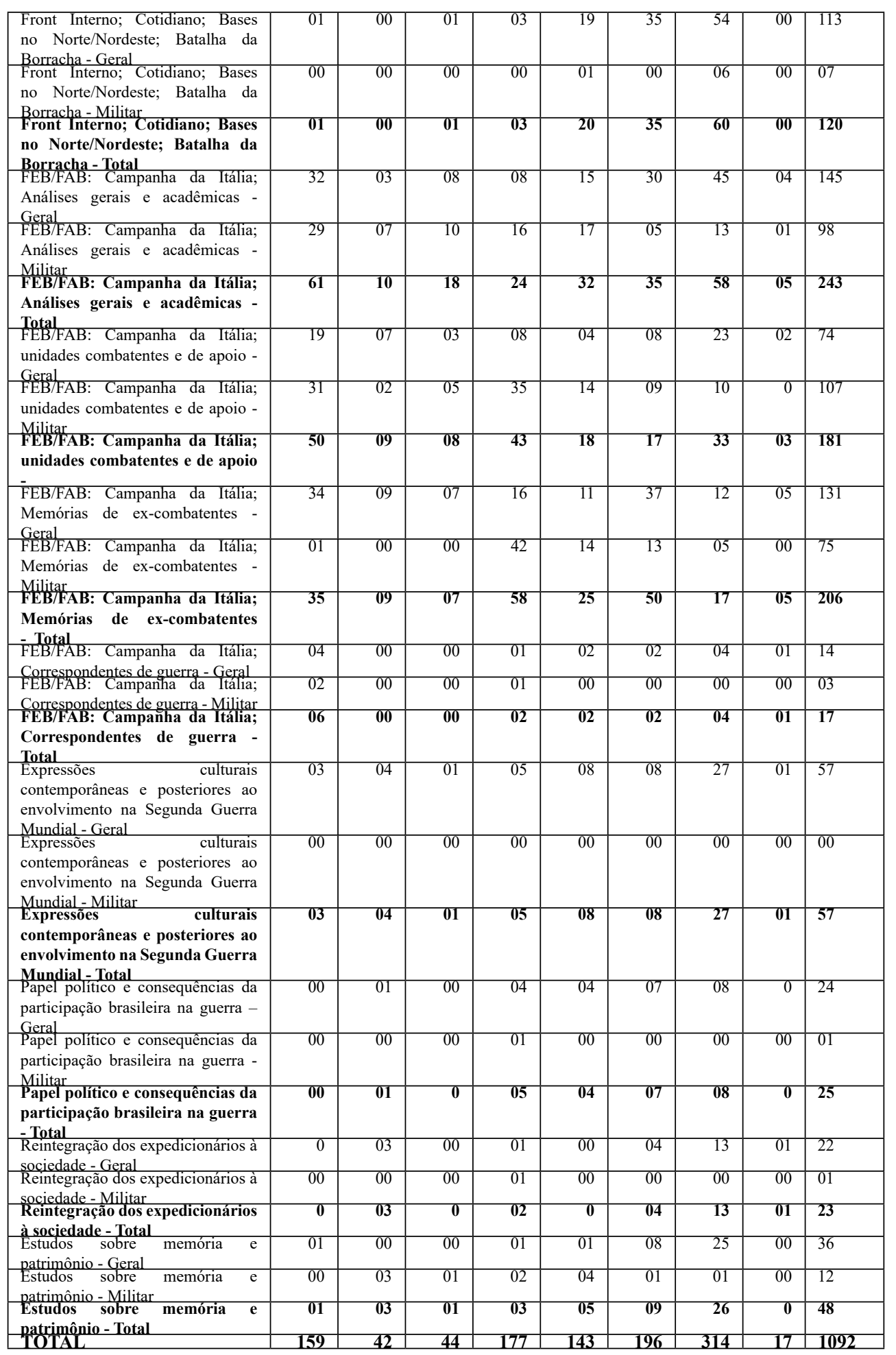

Fonte: Levantamento da Produção Bibliográfica sobre a Participação do Brasil na Segunda Guerra Mundial. Projeto de Pesquisa "Força Expedicionária Brasileira: história e historiografia", CNPqUniversidade Estadual de Londrina, 2010-2015. 
Tabela 5 - Publicações para o público geral/público profissional, por décadas

\begin{tabular}{|l|r|r|r|r|r|r|r|r|r|}
\hline & $\mathbf{1 9 4 5}$ & $\mathbf{1 9 5 6}$ & $\mathbf{1 9 6 6}$ & $\mathbf{1 9 7 6}$ & $\mathbf{1 9 8 6}$ & $\mathbf{1 9 9 6}$ & $\mathbf{2 0 0 6}$ & S/d & Total \\
& $\mathbf{a}$ & $\mathbf{a}$ & $\mathbf{a}$ & $\mathbf{a}$ & $\mathbf{a}$ & $\mathbf{a}$ & $\mathbf{a}$ & & \\
\hline Público & 96 & $\mathbf{1 9 6 5}$ & $\mathbf{1 9 7 5}$ & $\mathbf{1 9 8 5}$ & $\mathbf{1 9 9 5}$ & $\mathbf{2 0 0 5}$ & $\mathbf{2 0 1 5}$ & \\
Geral & $60,4 \%$ & $71,4 \%$ & $56,8 \%$ & $37,8 \%$ & $57,3 \%$ & $81,6 \%$ & $86,3 \%$ & $94.1 \%$ & $68,4 \%$ \\
\hline Público & 63 & 12 & 19 & 110 & 61 & 36 & 43 & 01 & 345 \\
Profissional & $39,6 \%$ & $28,6 \%$ & $43,2 \%$ & $62,2 \%$ & $42,3 \%$ & $18,4 \%$ & $13,7 \%$ & $5,9 \%$ & $31,6 \%$ \\
Militar & & & & & & & & & \\
& & & & & & & & & \\
\hline Total & $\mathbf{1 5 9}$ & $\mathbf{4 2}$ & $\mathbf{4 4}$ & $\mathbf{1 7 7}$ & $\mathbf{1 4 3}$ & $\mathbf{1 9 6}$ & $\mathbf{3 1 4}$ & $\mathbf{1 7}$ & $\mathbf{1 0 9 2}$ \\
\hline
\end{tabular}

Fonte: Levantamento da Produção Bibliográfica sobre a Participação do Brasil na Segunda Guerra Mundial. Projeto de Pesquisa "Força Expedicionária Brasileira: história e historiografia", CNPqUniversidade Estadual de Londrina, 2010-2015.

Nota-se que, com exceção da década entre 1976-1985, quando a produção mais profissionalizada ultrapassou, em publicações, a produção voltada para o público civil, e na década seguinte (1986-2005), quando houve um relativo equilíbrio, a proporção média de $2 / 3$ das produções para o público geral foi mantida em todos os outros períodos. Constata-se também o crecimento significativo da produção para o público geral nas últimas duas décadas, sendo menor a proporção de publicações sobre o tema endereçadas mais especificamente ao público militar. É importante mostrar que, examinandose os títulos das publicações militares das duas últimas décadas, nota-se que não se trata de diminuição da importância do tema nas revistas militares, mas sim a expansão exponencial da produção "civil" do tema nas iniciativas editoriais.

\section{O desenvolvimento histórico das publicações}

Avaliando-se os dados numéricos, chama a atenção o volume crescente de publicações que dizem respeito ao envolvimento do país na guerra. Conquanto se constate que, nas últimas décadas, foram proporcionadas maiores facilidades de publicação, em todos os temas da história brasileira e mundial, é notável o aumento do interesse de leitores e de pesquisadores sobre a participação do Brasil na Segunda Guerra Mundial.

Contudo, nem todas as dimensões dessa participação apresentam semelhante crescimento. Ao longo dos setenta anos pesquisados, houve temas que concentraram a preferência de autores e leitores por algum tempo e depois foram suplantados por outros temas e abordagens. Por outro lado, alguns tópicos, que foram pouco, ou não foram abordados nas primeiras décadas pós-guerra, se tornaram alvo de maior interesse e publicação por parte de autores, editores e público leitor. Há, ainda, alguns temas que apresentam picos alternados de expressiva e declinante produção.

Dentre os temas que estão perdendo espaço destaca-se o relacionado 
à história das unidades expedicionárias (incluindo o Grupo de Aviação de Caça), que, no imediato pós-guerra, teve grande volume de produção vinculado às publicações profissionais militares e, com o tempo, foi perdendo espaço. Essa diminuição de espaço é maior se verificarmos, dentro desse tema, o aumento mais recente da publicação de histórias que envolvem unidades nãocombatentes, como serviço médico, enfermagem, logística, serviço religioso, alimentação e Pelotão de Sepultamento. Esses tópicos têm sido abordados, como era de se esperar, por pesquisadores civis.

Outro tema, cujo volume de publicações tem diminuído, foi o das memórias individuais escritas por ex-combatentes, familiares e amigos. Porém, diferentemente do caso das unidades expedicionárias, a razão mais plausível para essa diminuição é o esgotamento do gênero nas décadas anteriores, pois, desde o fim da guerra, foram editadas memórias e diários de guerra dos veteranos da FEB e FAB, e com o passar do tempo e o falecimento crescente dos veteranos de guerra, ficou cada vez mais reduzido o número de ex-combatentes que desejaram preservar para a posteridade suas experiências cuja memória ainda não havia sido publicada. É doloroso constatar que, com a progressiva extinção física do grupo de veteranos de guerra, esse item tende a reduzir-se cada vez mais.

Alguns temas oscilam entre momentos de produção ora modesta e ora expressiva. Um dos casos é o tema da Entrada do Brasil na Segunda Guerra Mundial/Relações Internacionais. Nas três primeiras décadas esse tema praticamente inexistiu. Na década entre 1976 e 1985, porém, despontaram os estudos clássicos sobre o tema, como os trabalhos dos brazilianistas Stanley Hilton e Frank D. McCann e dos brasileiros Roberto Gambini, Gerson Moura, Ricardo Seintenfus e Luiz Alberto Moniz Bandeira ${ }^{8}$. A retomada desse tópico ocorreu de maneira vigorosa nas duas últimas décadas. Nesses estudos, os desafios e impasses da política externa brasileira, suas limitações e projeções, estão presentes nas abordagens sobre a entrada do país na guerra, inclusive a política pendular de Vargas. A perspectiva da participação brasileira, na visão de estadunidenses, britânicos, alemães e italianos, também está desenvolvida nesse tópico, assim como os estudos sobre a aliança entre Brasil e os Estados Unidos 9 . De maneira análoga, o impacto da guerra na América Latina e as relações com os países vizinhos, especialmente com a Argentina, contam com bons estudos, assim como as abordagens sobre a segurança hemisférica das Américas e o papel brasileiro. Três subáreas de estudo estão crescendo nas duas últimas décadas: os episódios de espionagem e contra-espionagem, a política cultural de Boa Vizinhança durante a guerra e, mais especificamente, os estudos sobre a política externa e a aliança militar entre Brasil e Estados Unidos, que não se circunscreviam apenas à Campanha da Itália e à proteção do Atlântico Sul ${ }^{10}$.

A Guerra no Atlântico Sul teve um destaque mais intenso na década 
entre 1976 e 1985, sobretudo após a publicação do estudo de Jürgen Rower ${ }^{11}$, sobre os torpedeamentos dos submarinos alemães na costa brasileira e, na última década, com um grupo maior de historiadores desenvolvendo pesquisas baseadas em documentos até então inéditos da Marinha alemã, sobre os ataques dos submarinos, e com documentação oral e escrita das localidades do litoral onde ocorreram os torpedeamentos ${ }^{12}$.

Alguns desses estudos sobre a vida nas cidades do litoral e o impacto da guerra chamam a atenção para o crescimento significativo de estudos sobre as diversas dimensões do Front Interno: o cotidiano das cidades, a mobilização econômica e cultural, as relações entre brasileiros e estadunidenses nas bases militares dos Aliados, o racionamento de produtos e, por último mas não menos importante, pois trata-se de uma subárea em franco crescimento, as tensões entre descendentes de "súditos do Eixo" no Brasil, e a população brasileira em tempos de guerra ${ }^{13}$.

Uma área que manteve o interesse e o ritmo de produção bibliográfica, não obstante variassem os tópicos, a abordagem e o conteúdo ao longo dos anos, foi a relacionada aos estudos gerais da Campanha da Itália. Na última década tornaram-se frequentes as publicações sobre eventos militares de campanha, as trajetórias de cidadãos-soldados de municípios específicos e um subtema que tem crescido bastante nas últimas duas décadas, que é o relacionado aos descendentes do Eixo na Força Expedicionária Brasileira ${ }^{14}$.

Algumas áreas ficaram por longo tempo praticamente sem publicações, e nos últimos 20 anos estas tiveram um crescimento significativo: uma delas trata das Expressões Culturais do Brasil na guerra e sobre o país naquele conflito. Além de romances e ficção, houve estudos sobre a música, sobre a iconografia e sobre o cinema documentário e ficcional dessa participação ${ }^{15}$.

Os estudos que abordam o pós-guerra, em diversas dimensões - a reintegração dos combatentes, as consequências políticas e a construção de uma memória social através das mais diversas estratégias de lembranças e comemorações tiveram trajetórias semelhantes: raros nas quatro primeiras décadas após a guerra, e crescentes a partir da década de 1990. Para tanto foram importantes as fontes das associações de ex-combatentes, que proporcionavam não apenas as memórias escritas e orais dos veteranos, mas sobretudo os acervos dos trabalhos desenvolvidos pelas próprias associações ${ }^{16}$.

\section{Problemas e soluções para o crescimento quantitativo e qualitativo da área: um balanço provisório}

Ao longo deste estudo, pode-se afirmar que o desenvolvimento da historiografia da participação brasileira na Segunda Guerra Mundial apresenta um avanço quantitativo notável nos últimos anos, bem como uma expansão dos temas e abordagens, que tende a ampliar o público leitor e as iniciativas 
de novas pesquisas.

Nesse sentido, é essencial compreender o papel desenvolvido pelas instituições militares, pelas universidades e pelas editoras. As instituições militares foram e são imprescindíveis para o desenvolvimento dos temas ligados ao Brasil na guerra. Estimularam os esforços de publicação nos anos seguintes ao fim das hostilidades, principalmente através das revistas profissionais, que publicaram dezenas de artigos, a maioria vinculada às experiências de combate e logística da Campanha da Itália. Nas décadas seguintes, mesmo em menor proporção ao ocorrido no pós-guerra, continuaram publicando sobre o assunto e, através de suas editoras, foram responsáveis pelo lançamento de dezenas de livros de relatos, memórias e análises sobre o envolvimento do país na guerra. Essas instituições mantêm até hoje uma tradição de publicação sobre o tema do Brasil na guerra, embora haja uma predominância quantitativa e proporcional de obras sobre a participação das forças terrestres, em relação às da Marinha e da Aeronáutica.

Uma característica, porém, marcou uma parte dessa produção editorial, voltada não somente para o público profissional, mas também para o civil: cultivou-se um certo tom laudatório e apologético, sem revisões críticas dos problemas institucionais, do papel das lideranças febianas na formação e treinamento da divisão, no planejamento e desempenho das missões, especialmente em relação às ações do Comandante da FEB, Marechal Mascarenhas de Moraes, elevado em vários livros e artigos ao patamar de homenagem hagiográfica. Os equívocos e problemas da Campanha da Itália - e foram muitos - encontraram nessa bibliografia específica muito pouca referência. As exceções foram publicações fora do ambiente institucional, como o livro Depoimentos do Oficiais da Reserva da F.E.B. e Verdades e Vergonhas da $F E B^{17}$. Essa marca de literatura "chapa-branca" foi danosa para o desenvolvimento de estudos sobre o assunto até a década de 1980 e, conjugada com uma visão de senso comum segundo a qual não havia distinção entre os expedicionários e as forças armadas, que comandavam um regime de exceção no país desde 1964, chegou a provocar a edição de obras com o intuito exatamente oposto, ou seja, fazer da Campanha da FEB na Itália um arrolamento de mazelas, das quais se destaca "O Outro Lado da Glória", do jornalista William Waack ${ }^{18}$.

Outra característica dessas obras, vinculadas a um ambiente institucional pouco propenso às avaliações críticas é a rara citação de uma pelas outras, ou seja, há muito pouca revisão interpares da bibliografia. A exceção parece ser o livro atribuído a Mascarenhas de Moraes, A FEB pelo seu Comandante, citado mais frequentemente, porém com escassa apreciação crítica ${ }^{19}$. Com a sua primeira edição data de 1947 , essa obra consiste no tratamento editorial e institucional militar do "Relatório Secreto da FEB" e pode ser considerada a "história oficial" da FEB, ou o mais próximo que se tem de uma história 
dessa natureza.

Por mais que tenham uma pauta consolidada de produção bibliográfica, as instituições militares não são as que têm maior bibliografia sobre a participação na Segunda Guerra. Na verdade, as iniciativas editoriais não vinculadas à instituição militar foram responsáveis, ao longo de sete décadas, por publicar a maior parte da produção bibliográfica. O único período em que, estatisticamente, foram suplantadas pelas iniciativas ligadas à instituição militar foi o da década entre 1976 e 1985, o que pode ser explicado, parcialmente pela distorção estatística, já citada anteriormente, do número especial dedicado ao centenário de Mascarenhas de Moraes em 1983.

Deve ser ressaltado que essa produção "civil" consiste, até meados da década de 1980, exclusivamente de livros, coletâneas e (poucos) artigos em periódicos científicos. Em outros termos, os trabalhos produzidos pela historiografia universitária (teses de doutorado e livre-docência; dissertações de mestrado, monografias) apareceram somente nas últimas três décadas. Assim, é possível inferir que o tema do Brasil na Segunda Guerra, mesmo nas primeiras décadas após seu fim, era uma iniciativa que contava com um público leitor com expectativa de consumir livros deste tema. As iniciativas acadêmicas se somaram tardiamente a tal produção voltada para o público geral.

A notável expansão das publicações referentes a esse tema nos últimos vinte anos, pode ser explicada além das projeções de um público leitor ávido por novidades na área; em primeiro lugar, pelo crescimento das abordagens regionais, que incorpora também novos acervos documentais, até então desconhecidos ou pouco estudados; em segundo lugar, por uma procura maior, da parte de jovens pesquisadores, por novas histórias e abordagens a respeito da participação do país na guerra, em suas variadas dimensões. Em terceiro lugar, pela publicação de dissertações de mestrado e teses de doutorado por editoras comerciais e universitárias, o que mostra que há um mercado consumidor dessa bibliografia.

Há, portanto, um público, relativamente pequeno mas fiel e crescente, que consome a produção historiográfica sobre o Brasil envolvido na guerra. Uma das possíveis razões para tal crescimento está no desenvolvimento da própria disciplina histórica, que incorpora métodos e fontes documentais variados. Outra razão pode ser a procura, cada vez maior, de pesquisadores militares de carreira nas Forças Armadas, por desenvolver projetos de pesquisa em cursos de pós-graduação stricto sensu no sistema universitário brasileiro. Esse fenômeno ajuda a "quebrar o gelo" entre pesquisadores civis e militares, e é reforçado pela abertura cada vez maior de arquivos históricos das Forças Armadas a pesquisadores civis, com benefícios mútuos. Por outro lado, a maior integração confere, à produção bibliográfica mais recente, abordagens com mais cientificidade e menos posicionamentos laudatórios.

Há uma limitação séria, porém, a essa expansão: o presente e o futuro 
das fontes documentais. Os acervos históricos do Arquivo Histórico do Exército e de seus pares da Marinha e Aeronáutica não contêm toda a documentação do tema. No caso do Arquivo Histórico do Exército, uma parte significativa dos acervos do processo de seleção da FEB e da Campanha da Itália está pulverizada em várias unidades da força terrestre pelo Brasil, sem catalogação e até mesmo sem conservação adequada. As limitações orçamentárias das Forças Armadas no país não permitem que seja feito um esforço para inventariar, catalogar e centralizar o material, em nível nacional. Isso faz com que, em certos tópicos, historiadores tenham que trabalhar com amostragens, e não com acervos documentais completos.

Se a dispersão dos arquivos militares é um problema sério, o desaparecimento progressivo dos veteranos é tragicamente preocupante: além da perda natural desses agentes de memória, há uma tendência de fechamento das associações de ex-combatentes, com o consequente risco de abandono, dispersão ou mesmo comercialização de acervos documentais e de cultura patrimonial. O destino desses acervos dependerá, em grande parte, dos familiares e amigos dos veteranos falecidos e de sua vontade de abrir acervos pessoais às novas gerações de pesquisadores.

\section{Considerações Finais}

Em síntese, o que esta pesquisa procurou mostrar é que, diferentemente do que comumente se pensa, há uma grande produção bibliográfica sobre os brasileiros na Segunda Guerra Mundial e uma sólida demanda por mais e variadas publicações, por parte de leitores e pesquisadores, nas universidades, nas instituições militares e no mercado consumidor editorial. Os esforços de pesquisa e publicação estão, aos poucos, unindo gerações de historiadores e leitores civis e militares. Os malefícios da literatura laudatória estão cada vez mais distantes do fluxo da produção bibliográfica sobre o tema. Trata-se de uma produção que, submetida às regras metodológicas e teóricas mais consistentes, está proporcionando um ganho crescente na qualidade dos trabalhos.

Contudo, algumas limitações, devidas ao problema dos acervos documentais, devem ser vencidas com urgência, para que a tendência ao aperfeiçoamento qualitativo e expansão qualitiva se consolide nesse ramo da historiografia.

Há, portanto, imensos campos a pesquisar visando a publicação. E com o fito de reivindicar mais espaço nas narrativas históricas brasileiras na memória coletiva, na produção didática e historiografia profissional universitária, é necessário unir, de maneira bem proveitosa, a expansão das obras e os ganhos indiscutíveis de qualidade historiográfica.

\section{NOTAS}


1 RUAS SANTOS, Francisco. Fontes para a História da FEB. Rio Rio de Janeiro: Biblioteca do Exército Editora, 1958.

2 CARDOSO, Ney Eichler. A FEB e a História Militar. A Defesa Nacional. Ano 56, No. 638, p. 139-148, Jul-Ago 1971; CARDOSO, Ney Eichler. A FEB e a História Militar. Revista de História. Universidade de São Paulo, Ano 24, vol. 47, 1973.

3 FERRAZ, Francisco César Alves. Os livros didáticos e a participação brasileira na Segunda Guerra Mundial. Luso-Brazilian Review, v. 47, n. 1, June 2010, p. 11-39.

4 A publicação do Guia Bibliográfico - O Brasil e a Segunda Guerra Mundial está planejada para o final de 2016.

5 FARIAS, Osvaldo Cordeiro de. Meio século de combate. Diálogo com Cordeiro de Farias, Aspásia Camargo, Walder de Goes. Rio de Janeiro: Nova Fronteira, 1981.

6 A primeira década (1945-1955) possui onze anos, mas o ano de 1945 foi incluído por sua representatividade na historiografia do tema e porque a maior parte das obras levantadas nesse ano foram publicadas nos últimos meses do segundo semestre.

7 . BARBOSA, João Felipe Sampaio. Regresso e desmobilização da FEB: problemas e consequências. A Defesa Nacional. Rio de Janeiro, Ano 71, № 719, mai.jun. 1985.

8 Nesta nota, e nas seguintes, serão arrolados apenas alguns dos trabalhos considerados representativos de cada área de estudo. O autor está ciente do risco de cometer injustiças e citará, nessa e nas próximas notas, apenas livros ou teses de doutorado, por mais que possam ser encontrados artigos, capítulos de livros e dissertações de mestrado seminais para as respectivas áreas de estudos. Nesse tópico, algumas das obras mais representativas da historiografia são: McCANN, Frank. The Brazilian-American Alliance, 1937-1945. Princeton Princeton University Press, 1973; GAMBINI, Roberto. O Duplo Jogo de Getúlio Vargas. São Paulo: Editora Símbolo, 1977; HILTON, Stanley. O Brasil e a Crise Internacional (1930-1945). Rio de Janeiro: Civilização Brasileira, 1977; HILTON, Stanley. Suástica sobre o Brasil. A história da espionagem alemã no Brasil (1939-1944). Rio de Janeiro: Civilização Brasileira, 1977; BANDEIRA, Moniz. Presença dos Estados Unidos no Brasil (Dois séculos de História). Rio de Janeiro: Civilização Brasileira, 1978; MOURA, Gerson. Autonomia na Dependência. Rio de Janeiro: Nova Fronteira, 1980; HILTON, Stanley. Hitler's Secret War in South America, 1939-1945. German Military Espionage and Allied Counterespionage in Brazil. New York: Ballantine Books, 1981; HILTON, Stanley. A Guerra secreta de Hitler no Brasil, 1939-1945, Rio de Janeiro: Nova Fronteira, 1983; SEITENFUS, Ricardo Antônio Silva. O Brasil de Getúlio Vargas e a formação dos blocos: 1930-1942. O processo de envolvimento brasileiro na II Guerra Mundial. São Paulo: Ed. Nacional; (Brasília): INL, Fundação Nacional PróMemória, 1985.

9 Cf. DAVIS, Sonny. A brotherhood of arms: Brazil-United States military relations 19451977. Niwot: University Press of Colorado, 1996; CORSI, Francisco L. Estado Novo: política externa e projeto nacional. São Paulo: Editora UNESP, 2000; CONN, Stetson; FAIRCHILD, Byron. A Estrutura de Defesa do Hemisfério Ocidental. Rio de Janeiro: Biblioteca do Exército Editora, 2000; ALVES, Vagner Camilo. O Brasil e a Segunda Guerra Mundial: história de um envolvimento forçado. Rio de Janeiro: Ed. Da PUC-RJ, 2002; ALVES, Vagner Camilo. Da Itália À Coréia: Decisões sobre Ir ou não à Guerra. Belo Horizonte e Rio de Janeiro: Editora UFMG e IUPERJ, 2007; RAHMEIER, Andrea Helena Petry. Relações diplomáticas e militares entre a Alemanha e o Brasil: da proximidade ao rompimento (1937-1942). Tese de Doutorado em História. Porto Alegre, Pontifícia Universidade Católica do Rio Grande do Sul (PUCRS), 2009; MOURA, Gerson. Relações Exteriores do Brasil (1939-1950): mudanças na natureza das relações Brasil-Estados Unidos durante e após a Segunda Guerra Mundial. 
Brasília: FUNAG, 2012; MONTEIRO, Erica G. Daniel . Quando a Guerra é um negócio: F. D. Roosevelt, iniciativa privada e relações interamericanas durante a II Guerra Mundial. Curitiba: Prismas, 2014; OLIVEIRA, Dennison. Aliança Brasil-EUA: nova história do Brasil na Segunda Guerra Mundial. Curitiba: Juruá, 2015.

10 Sobre as relações com os países vizinhos e as estratégias de "boa vizinhança", Cf. BETHELL, Leslie. A América Latina entre a Segunda Guerra Mundial e a Guerra Fria. Rio de Janeiro: Paz e Terra, 1996; JUNQUEIRA, Mary Anne . Ao Sul do Rio Grande. Imaginando a América Latina em Seleções. Oeste, Wilderness e Fronteira (1942-1970). Bragança Paulista: Editora da Universidade São Francisco, 2000; BANDEIRA, Moniz. Brasil, Argentina e Estados Unidos - conflito e integração na América do Sul (Da Tríplice Aliança ao Mercosul, 1870-2003). Rio de Janeiro: Revan, 2003; SMITH, Joseph. Brazil: Benefits of Cooperation. In LEONARD, Thomas M.; BRATZEL, John F. Latin America During World War II. Rowman \& Littlefield Publishers, Inc., 2007; SANTOS, Raquel Paz dos. Um olhar sobre o país vizinho: representações do Brasil e da Argentina no contexto das relações diplomáticas (1930-1954). Tese de Doutorado. Programa de Pós-graduação em História da UFF. Rio de Janeiro, 2008; Sobre o impacto cultural da política de boa vizinhança, o clássico continua sendo a obra de Antônio Pedro Tota, O Imperialismo Sedutor: a americanização do Brasil na época da Segunda Guerra Mundial. (São Paulo: Companhia das Letras, 2000).

11 ROWER, Jürgen. Operações navais da Alemanha no litoral do Brasil durante a Segunda Guerra Mundial. Navigator: subsídios para a história marítima do Brasil. N. 18, Rio de Janeiro, jan/dez 1982.

12 SANDER, Roberto. O Brasil na mira de Hitler: a história do afundamento de navios brasileiros pelos nazistas. Rio de Janeiro: Objetiva, 2007; ARANTES, Marcus Vinicius de Lima. Torpedo: o terror do Atlântico. O torpedeamento de navios brasileiros e o patrulhamento do Atlântico Sul. Rio de Janeiro: Livre-Expressão, 2012; MONTEIRO, Marcelo. U-507: o submarino que afundou o Brasil na Segunda Guerra Mundial. Salto, SP: Schoba, 2012.; PEREIRA, Durval Lourenço. Operação Brasil - o ataque alemão que mudou o curso da Segunda Guerra Mundial. São Paulo: Editora Contexto, 2015.

13 MARTINELlO, Pedro. A "Batalha da Borracha” na Segunda Guerra Mundial e suas consequências para o Vale Amazônico. Tese de Doutorado em História. São Paulo: FFLCHUSP, 1985; CARNEIRO, Maria Luiza Tucci. O anti-semitismo na era Vargas (1930-1945). São Paulo: Brasiliense, 1988; PERAZZO, Priscila F. O perigo alemão e a repressão policial no Estado Novo. São Paulo: Imprensa Oficial/Arquivo do Estado, 1999; CYTRYNOWICZ, Roney. Guerra sem guerra: a mobilização e o cotidiano em São Paulo durante a Segunda Guerra Mundial. São Paulo: Ed. da Universidade de São Paulo/Geração Editorial, 2000; FÁVERI, Marlene de. Memórias de uma (outra) guerra: cotidiano e medo durante a Segunda Guerra em Santa Catarina. 2ed. Itajaí: Ed. Da Univali; Florianópolis: Ed. Da UFSC, 2002; MORALES, Lúcia Arraias: Vai e Vem, Vira e Volta: as Rotas Dos Soldados da Borracha. Coleção Outros Diálogos. Fortaleza/ São Paulo: Governo do Estado do Ceará/. Annablume, 2002; PERAZZO, Priscila F. Prisioneiros de Guerra: os cidadãos do Eixo nos campos de concentração brasileiros (1942-1945). Tese de Doutorado (Doutorado em História) Universidade de São Paulo, São Paulo. 2002; MOUTINHO, Augusto César Machado. A sombra da guerra - o medo e a sobrevivência em um povoado baiano durante a Segunda Guerra Mundial. Quarteto Editora, 2005; SECRETO, María Verónica. Soldados da Borracha: Trabalhadores Entre o Sertão e a Amazônia no Governo Vargas. São Paulo: Editora Fundação Perseu Abramo, 2007; SILVA, Marina Helena Chaves. Vivendo com o outro: os alemães na Bahia no período da II Guerra Mundial. (Tese de Doutorado em História), Salvador: UFBA, 2007; SHIZUNO, Elena Camargo. Os imigrantes japoneses na Segunda Guerra Mundial: bandeirantes do Oriente o perigo amarelo no Brasil. Londrina: Eduel, 2010; MAYNARD, 
Dilton Cândido Santos . Dias de Luta: Sergipe durante a Segunda Guerra Mundial. Rio de Janeiro/S. Cristóvão: Multifoco/EDUFS/EDUFCG, 2011; MONTEIRO, Jorgemar; FAVACHO, Enio. O Amazonas na $2^{a}$ Guerra Mundial. Notícias da participação do Norte do Brasil. Bauru, SP, Canal 6 editora, 2011.

14 A lista é imensa e qualquer seleção seria arbitrária. Consciente disso, o autor arrola títulos que foram e são referências constantes, citadas em vários estudos e/ou outras obras deste e de outros tópicos. Também foram incluídas as memórias escritas dos combatentes e dos correspondentes de guerra: BRAGA, Rubem. Com a FEB na Itália: crônicas. Rio de Janeiro: Zelio Valverde, 1945; SILVEIRA, Joel. Histórias de Pracinha; Oito Meses Com a Força Expedicionária Brasileira. Rio de Janeiro: Cia. Editora Leitura, 1945; HALLAWELL, Francis (ed.). Scatolettas da Italia. Seleção de reportagens dos correspondentes de guerra brasileiros na Itália, irradiadas pela B.B.C. Londres: BBC, 1946; SILVEIRA, Antorildo. O Sexto Regimento de Infantaria Expedicionária (Fatos da campanha do $6^{\circ}$. R.I. no território da Itália. Rio de Janeiro: Biblioteca Militar, 1946; MASCARENHAS DE MORAES, J. B. A FEB pelo seu comandante. São Paulo: Instituto Progresso Editorial, 1947; ARRUDA, Demócrito, et alii, Depoimento dos Oficiais de Reserva sobre a FEB. São Paulo: Instituto Progresso Editorial, 1947; SILVEIRA, Joaquim Xavier da. Cruzes brancas-diário de um pracinha. Rio de Janeiro: José Olympio, 1947; ANDRADE, Delmiro P. O $11^{\circ}$ R.I. na $2^{a}$ Guerra Mundial. Rio de Janeiro: Biblioteca do Exército, 1950. CALDAS, Mirandolino. O Posto Avançado de Neuro Psiquiatria da FEB. Rio de Janeiro: Biblioteca do Exército, 1950; GONÇALVES, Carlos Paiva. Seleção Médica do Pessoal da FEB, História, funcionamento e dados estatísticos. Rio de Janeiro, Biblioteca do Exército, 1951; CARVALHO, Nelson Rodrigues de. Do Terço Velho ao Sampaio da FEB. Rio de Janeiro: Biblioteca do Exército, 1953; ALBUQUERQUE, Bento Costa Lima Leite de. Justiça Militar na Campanha da Itália:Constituição, Legislação, Decisões. Fortaleza: Imprensa Oficial, 1958; PERDIGÃO, Luiz Felipe. Missão de guerra: os expedicionários da FAB na guerra européia. Rio de Janeiro: Biblioteca do Exército, 1958; CASTELLO BRANCO, Manuel Thomaz. O Brasil na II Grande Guerra. Rio de Janeiro: Biblioteca do Exército Editora, 1960; BORGES FORTES, Heitor. A Artilharia Divisionária da $1{ }^{a}$ Divisão de Infantaria Expedicionária na Campanha da Itália. Rio de Janeiro: Biblioteca do Exército, 1962; SCHNAIDERMAN, Boris. Guerra em surdina: histórias do Brasil na Segunda Guerra Mundial. São Paulo: Brasiliense, 1964; BRAYNER, Floriano de Lima. A verdade sobre a FEB (memórias de um chefe de Estado-Maior na Itália). Rio de Janeiro: Civilização Brasileira, 1968; RODRIGUES, Agostinho José. Segundo Pelotão, Oitava Companhia. São Paulo: Edameris, 1969; REIS, Edgardo Moutinho dos. Exército de Padioleiros e Bisturis. Rio de Janeiro, 1969; LINS, Maria de Lourdes Ferreira. A Força Expedicionária Brasileira: uma tentativa de interpretação. São Paulo: Ed. Unidas, 1972; RODRIGUES, Agostinho José. Terceiro Batalhão - o Lapa Azul. Rio de Janeiro: Biblioteca do Exército, 1976; LIMA, Rui Moreira. Senta a Pua! Rio de Janeiro: Biblioteca do Exército Editora, 1980; SOARES, Leonércio. Verdades e Vergonhas da Força Expedicionária Brasileira. Curitiba, Ed. do autor, 1984; WAACK, William. As duas faces da glória. A FEB vista pelos seus aliados e inimigos. Rio de Janeiro: Nova Fronteira, 1985; SILVEIRA, Joaquim Xavier. A FEB por um soldado. Rio de Janeiro: Nova Fronteira, 1989; MAXIMIANO, Cesar Campiani. Onde estão os nossos heróis? Uma breve história dos brasileiros na $2^{a}$ Guerra. São Paulo: Atlas, 1995; BONALUME NETO, Ricardo. A Nossa Segunda Guerra: os brasileiros em combate, 19421945. Rio de Janeiro: Expressão e Cultura, 1995; UDIHARA, Massaki. Um médico brasileiro no front. Diário de Massaki Udihara na II Guerra Mundial. São Paulo: Hacker Editores; Narrativa Um; Imprensa Oficial do Estado; Museu Histórico de Imigração japonesa no Brasil, 2002;OLIVEIRA, Dennison. Os Soldados Alemães de Vargas. Curitiba: Juruá Editora, 2008; 2008. OLIVEIRA, Dennison. Os soldados brasileiros de Hitler. Curitiba: Editora Juruá Ltda., 2008; MAXIMIANO, Cesar Campiani. Barbudos, sujos e fatigados: soldados brasileiros na 
Segunda Guerra Mundial. São Paulo: Grua, 2010.

15 SOUSA, Marquilando Borges de. Rádio e Propaganda Política: Brasil e México Sob a Mira Norte-Americana Durante a Segunda Guerra. São Paulo: Annablume, 2004; COLIN, Cida; ABREU, João Batista de (orgs.). Batalha Sonora: o rádio e a Segunda Guerra Mundial. Porto Alegre: EDIPUCRS, 2006; PEREIRA, Maria Elisa. Você Sabe de Onde Eu Venho? O Brasil Dos Cantos de Guerra (1942-1945). Tese de Doutorado. São Paulo: Universidade de Sao Paulo, 2009; BARROS, Orlando de . A Guerra dos Artistas: Dois episódios da história brasileira durante a Segunda Guerra Mundial. Rio de Janeiro: E-Papers, 2010; ;ESQUENAZI, Rose. O rádio na Segunda Guerra: no ar, Francis Hallawell, o Chico da BBC. Florianópolis: Insular, 2014; TOMAIN, Cassio. Documentário e o Brasil na Segunda Guerra Mundial: o antimilitarismo e o anticomunismo como matrizes sensíveis. São Paulo, SP: Intermeios; FAPESP, 2014.

16 Sobre o pós-guerra, tanto nas consequências políticas quanto nas estratégias de memória e esquecimento, Cf. SILVEIRA, Joel. As duas guerras da FEB. Rio de Janeiro: Idade Nova, 1965; MATTOS, João Baptista de. Os Monumentos Nacionais: a Força Expedicionária no bronze. Separata da Revista Militar Brasileira, Nº 1 e 2, jan e jun 1960; ROSENHECK, Uri. Fighting for Home Abroad: Remembrance and Oblivion of World War II in Brazil. PhD Dissertation. Atlanta: Emory University, 2011; RIBEIRO, Patrícia da Silva. Em luto e luta: construindo a memória da FEB. Tese de Doutorado em História, Política e Bens Culturais - Fundação Getúlio Vargas, RJ. 2013; SMALLMAN, Shawn. Fear \& Memory in the Brazilian Army \& Society, 1889-1954. Chapel Hill: The University of North Carolina Press, 2002; FERRAZ, Francisco César Alves. A guerra que não acabou: a reintegração social dos veteranos da Força Expedicionária Brasileira (1945-2000). Londrina: Editora da Universidade estadual de Londrina, 2012; PIOVEZAN, Adriane. Morrer na guerra: instituições, ritos e devoções no Brasil (1944-1967). Tese de Doutorado em História. Curitiba, Universidade Federal do Paraná, 2014.

17 Além desses, há o livro do Coronel Floriano da Lima Brayner, Chefe do Estado-Maior da FEB na Itália ( $A$ Verdade sobre a FEB..., op. cit.).Contudo, trata-se de uma obra em que há mais críticas a desafetos, como o então Coronel Humberto de Alencar Castello Branco, do que propriamente um exame pormenorizado da participação da FEB.

18 Para uma avaliação crítica rigorosa da obra do jornalista, Cf. McCann, Frank. A Força Expedicionária Brasileira na Campanha da Itália, 1944-1945. In: SILVEIRA, Joel; MITKE, Tassilo (eds.). A Luta dos Pracinhas. A FEB 50 anos depois - uma visão crítica. 3ed. revista e aumentada. Rio de Janeiro: Record, 1993, p. 265-287.

19 A exceção é a crítica feita no clássico Depoimentos dos Oficiais de Reserva da FEB.

\section{Artigo recebido em fevereiro de 2016. Aceito em junho de 2016.}

